\title{
A Comparative Study on Evaluating the Service Quality Attributes based on Kano Model: A Case of Low-cost Carrier and Full-service Carrier
}

\author{
Hyojeong Byun ${ }^{1}$, Byeongcheol Lee ${ }^{2}$, Jaehee Rye ${ }^{3}$ \\ ${ }^{1,2,3}$ Graduate School of Event and Convention Management, Kyonggi University, Seoul, Republic of \\ Korea
}

\begin{abstract}
The emergence and development of low-cost carriers(LCC) with competitive price is heating up the competition in the aviation market more, especially between low-cost carriers(LCC) and full-service carriers(FSC). Therefore, it became more important than ever to implement service differentiation strategies of each airline for securing customers and competitiveness. In this sense, the purpose of this study is to compare and assess the different expectations of the customers for airline service attributes pursued by FSCs and LCCs. Three main dimensions of airline service quality attributes (physical, human, and system service), were selected and this study clarified the service quality attributes of each airline carrier using Kano Model. Data were collected from Korean passengers who experienced both LCCs and FSCs for international or domestic flights. As results, this study demonstrated several differences in airline service quality attributes between FSCs and LCCs, which imply that each airline needs to adopt differential strategies to be more competitive. In particular, most physical-related attributes for FSCs were a 'must-be' dimension while the majority of attributes for LCCs was clarified 'one-dimensional' attribute. The current study also presented implications to be helpful in developing the quality of service and establishing marketing strategies for improvement in customer satisfaction.
\end{abstract}

\section{Introduction}

Since the mitigation and liberalization of aviation regulations in 1978, competition in the aviation industry has become more severe. As a by-product of such softer regulations led to the appearance of LCCs(Low-Cost Carrier), which is accelerating competition among airliners even further. In addition to the quantitative increase of LCCs, the operation strategies of LCCs that normally focused on domestic or short haul services are gradually spreading to international and long haul routes, and thus cannot no longer avoid competing with FSCs(Full-Service Carrier). Therefore improvement and strategic management of service quality that have a definitive impact on the selection of airline companies by customers are essential for both LCCs and FSCs to be competitive in the rapidly market [1]. In reality, not only are there differences in the service strategies and key services pursued by FSCs and LCCs [2], but there are also different standards and levels of expectations for customers to select and evaluate the service qualities of the two types of carrier. This represents that different standards must be applied for designing and managing services offered by LCCs to consumers compared to 
other larger airline companies. In this sense, the purpose of this study is to compare and assess the different expectations of customers for airline service quality attributes of FSCs and LCCs, which is conducted by using Kano Model and b) provide practical implications for the service quality management of FSCs and LCCs.

\section{Background}

\subsection{Airline service quality attributes}

Airline services are made up of tangible and intangible properties. Airline companies use tangible aircrafts to transport passengers and cargo to their destination, while passengers experience a number of intangible services such as hospitality of crew, comfort of seats, cabin services, and service frequency. In order to measure and evaluate such airline service quality, most studies have adopted the five measurement items of PZB [3-4]. Most studies related to airline service quality have focused on testing influential relationship among service quality attributes and outcome variables such as customer satisfaction, loyalty and so on [5-9]. Although customers have different expectations and evaluation criteria for the service quality provided by LCCs and FSCs, there has been less effort to distinguish and clarify airline service quality attributes according to different types of airline.

Studies related to airline service quality in the tourism field are mostly made up of studies that classify airline services by selected properties or by work fields such as physical, human, cabin, ground, and airline services [5-9]. Based on previous studies, this study selected three main airline service attributes to compare and analyze the difference per airline company: physical service, human service, and system service (see Table 1).

Table 1. Airline service quality attributes

\begin{tabular}{|c|c|c|}
\hline Service Quality & Attributes & Sources \\
\hline Physical Service & $\begin{array}{c}\text { Attractive fare } \\
\text { Safety } \\
\text { Aircraft type } \\
\text { Cabin cleanliness } \\
\text { Convenience of in-flight equipment } \\
\text { Food \& beverage }\end{array}$ & \multirow{3}{*}{$\begin{array}{c}\text { Chou et al. [4] } \\
\text { Etherington and } \operatorname{Var}[6] \\
\text { Toh and } \mathrm{Hu}[7] \\
\text { Liou and Tzeng [9] } \\
\text { Leong [11] } \\
\text { J.W et al. [12] }\end{array}$} \\
\hline Human Service & $\begin{array}{c}\text { Kindness } \\
\text { Accurate business knowledge \& reliability } \\
\text { Appearance of staffs } \\
\text { Staff's speed handling request }\end{array}$ & \\
\hline System Service & $\begin{array}{l}\text { Convenience of booking \& ticketing } \\
\text { Speed of check-in } \\
\text { On-time departure \& arrivals } \\
\text { On-time luggage delivery on arrival } \\
\text { Timeless of flight schedule } \\
\text { Seat assignment } \\
\text { Easy to refund }\end{array}$ & \\
\hline
\end{tabular}




\subsection{Kano model and analysis}

The Kano model clarifies product or service attributes based on how they are perceived by customers. The Kano model is also called a two-dimensional recognition method of quality and explains the relationship between the performance of products and services with customer satisfaction. Consumers have different satisfaction levels for the fulfillment levels of quality elements and when any quality element is not fulfilled, the satisfaction level drops greatly. However, when fulfilled, it has elements that do not raise the satisfaction level very much, while also having quality elements with opposite attributes [13]. In other words, it considers the consistency with the required conditions of users, as well as the subjective aspect of satisfaction and dissatisfaction, and the objective aspect of fulfilling and non-fulfilling [14]. The Kano model categorizes three major quality elements of customer anticipation for products or services and two potential quality elements. The constituents can be arranged as shown in (Table 2).

Table 2. Service quality classification of Kano Model

\begin{tabular}{|l|l|}
\hline \multicolumn{1}{|c|}{ Attributes } & \multicolumn{1}{|c|}{ Features } \\
\hline Must-be attributes & $\begin{array}{l}\text { Basic (or threshold)attributes perceived by customers and when } \\
\text { it is fulfilled, it is take for granted and does not give } \\
\text { satisfaction, but the absence or poor performance of these } \\
\text { attributes results in customer dissatisfaction }\end{array}$ \\
\hline One-dimensional attributes & $\begin{array}{l}\text { Quality attributes that are essential and elements that cause } \\
\text { satisfaction when fulfilled and dissatisfaction when not fulfilled }\end{array}$ \\
\hline Attractive(excitement) attributes & $\begin{array}{l}\text { Quality attribute that gives satisfaction by exceeding customer } \\
\text { anticipations, and a potential requirement that can give } \\
\text { happiness and satisfaction to customers, while not causing } \\
\text { dissatisfaction even if not provided }\end{array}$ \\
\hline Indifferent attributes & $\begin{array}{l}\text { Quality attribute that does not affect satisfaction or } \\
\text { dissatisfaction of customers }\end{array}$ \\
\hline Reverse attributes & $\begin{array}{l}\text { Quality attribute that causes dissatisfaction when fulfilled and } \\
\text { satisfaction when not fulfilled } \\
\text { When fulfilled, customers actually feel inconvenience and acts } \\
\text { as an obstacle for other services }\end{array}$ \\
\hline
\end{tabular}

In the Kano model, each question on service quality is in the form of a pair of asking both positive and negative questions. Under the assumption of the Kano Model that asks 'How would you feel if something does/does not?', it asks questions in opposite meanings of negative and positive. For answers to it, the positive and negative answer pairs for the five-point scales of 'Do not like', 'Can't help', 'No feeling', 'Must-be', 'Like' are procured [10]. This is then evaluated as one of the five quality attributes of 'attractive', 'must-be', 'one-dimensional', 'indifferent' and 'reverse'.

\section{Method}

\subsection{Data collection and analysis}

The questionnaire of this study was administered at the departure and arrival gates of Incheon and 
Gimpo Airport from July 30 to August 20, 2013. The study used the self-administered questionnaire. The population of this study was selected from Korean passengers who experienced both LCCs and FSCs for international or domestic flights. Based on literature review, the questionnaire was developed, and the service quality attributes of airline carriers were made up of three main components that consist of 21 items as shown in (Table 3). The 21 attributes were drafted using survey techniques (42 with positive/negative each) appropriate to the Kano model, and asked 8questions about the general characteristics of customers.

Table 3. Questionnaire

\begin{tabular}{|c|c|c|c|c|}
\hline items & Questionnaire format & Questions & Scale & Source \\
\hline Human Service & \multirow{3}{*}{$\begin{array}{c}\text { Kano`s positive } \& \\
\text { negative }\end{array}$} & 5 & \multirow{3}{*}{ Kano`s 5-point scale } & \multirow{3}{*}{$\begin{array}{c}\text { Toh \& Hu[7] } \\
\text { Liou \&Tzeng[9] } \\
\text { J.W et al.[12] }\end{array}$} \\
\hline Physical Service & & 9 & & \\
\hline System Service & & 7 & & \\
\hline $\begin{array}{c}\text { General } \\
\text { Characteristics }\end{array}$ & $\begin{array}{c}\text { Sex, age, job, } \\
\text { education, } \\
\text { purpose of travel }\end{array}$ & 8 & Nominal scale & \\
\hline Total & & 29 & & \\
\hline
\end{tabular}

In this study, the data collected through questionnaires were classified into 'attractive', 'one-dimensional', 'must-be', 'indifferent' and 'reverse' through the Kano model analysis. With regard to research process. First, the survey results were verified for feasibility of survey through reliability analysis using the SPSS20.0 statistics package, Second, in order to identify the demographic information of participants, frequency analysis was carried out and lastly, the service quality difference of LCCs and FSCs were compared and analyzed by categorizing the service quality attributes per airline carrier type using the Kano model.

\section{Results}

\subsection{Demographic information}

A total of 350 questionnaires were handed out. 293 of them were collected and excluding 13 missing answers or judged to be insincere were excluded to analyze a total of 280 . In order to examine the demographical features of the respondents, frequency analysis was conducted. In result, $73(26.1 \%)$ were men and 203(73.9\%) were female, with 18(6.4\%) being in their teens, $108(38.6 \%)$ being in their $20 \mathrm{~s}, 86(30.7 \%)$ in their $30 \mathrm{~s}, 55(19.6 \%)$ in their $40 \mathrm{~s}, 12(4.3 \%)$ in their $50 \mathrm{~s}$ and $1(0.4 \%)$ in their $60 \mathrm{~s}$. For educational level, 150(53.6\%) were university, 46(17.1\%) were junior colleges, $41(14.6 \%)$ were graduate school, $30(10.7 \%)$ were high school, and $11(3.9 \%)$ were other.

\subsection{Validity and reliability test}

For validity test, an exploratory factor analysis was conducted on 21 positive questions of LCCs using the Varimax rotation method. Four factors were extracted with the eigen value 1.0, which were named aircraft, cabin service, employees, and flight system, and in combination this explained $60.944 \%$ of the total variance. The KMO values of extracted components were high at 0.921 , which is well above the recommendation limit of 0.5 . For reliability test, Cronbach`s Alpha value was used to assess 
internal consistency of items for service quality attributes, and its value ranged from 0.646 to 0.875 for each factor.

Table 4. Validity and reliability test

\begin{tabular}{|c|c|c|c|c|c|}
\hline \multicolumn{2}{|c|}{ Factors } & Items & $\begin{array}{l}\text { Standardized } \\
\text { factor loading }\end{array}$ & $\begin{array}{c}\% \text { of } \\
\text { Variance }\end{array}$ & $\begin{array}{c}\text { Cronbach's } \\
\text { Alpha }\end{array}$ \\
\hline \multirow{2}{*}{ 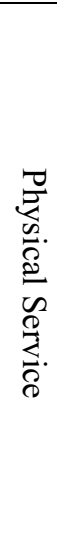 } & Aircraft & $\begin{array}{l}\text { safety } \\
\text { comfort of the seats } \\
\text { attractive ticket fare } \\
\text { cabin storage space } \\
\text { state-of-the-art in flight } \\
\text { equipment }\end{array}$ & $\begin{array}{l}.748 \\
.665 \\
.658 \\
.499 \\
.425\end{array}$ & 5.185 & .652 \\
\hline & $\begin{array}{l}\text { In-flight } \\
\text { service }\end{array}$ & $\begin{array}{l}\text { quality of the food \& beverage } \\
\text { availability of meal service } \\
\text { in-flight entertainment } \\
\text { cabin cleanliness }\end{array}$ & $\begin{array}{l}.739 \\
.736 \\
.709 \\
.497\end{array}$ & 6.212 & .875 \\
\hline 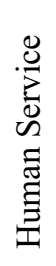 & Employee & $\begin{array}{l}\text { kindness } \\
\text { business knowledge \& skills } \\
\text { prompt responses to requests } \\
\text { appearance of employees } \\
\text { uniforms of employee }\end{array}$ & $\begin{array}{l}.788 \\
.731 \\
.642 \\
.634 \\
.591\end{array}$ & 7.486 & .747 \\
\hline 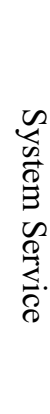 & Flight system & $\begin{array}{l}\text { on-time luggage delivery } \\
\text { convenient flight schedules } \\
\text { timeliness of flight } \\
\text { speed of check-in } \\
\text { easy to refund } \\
\text { convenience of booking \& } \\
\text { ticketing } \\
\text { seat assignment }\end{array}$ & $\begin{array}{l}.766 \\
.700 \\
.665 \\
.665 \\
.654 \\
.640 \\
.631\end{array}$ & 42.061 & .646 \\
\hline & & $.921(\mathrm{p}>0.001), \mathrm{df}=210$ & Square $=2$ & & \\
\hline
\end{tabular}

\subsection{Service quality classification by Kano model}

Upon carrying out survey with 21 positive/negative questions for LCCs and FSCs and checking the quality properties according to the Kano quality analysis table, it was found that among the nine physical services, 'advanced cabin facilities' and 'cabin cleanliness' were found to be both attractive and one-dimensional attributes for both airline types. Meanwhile, 'airline fare' was a one-dimensional attributes for LCCs and an attractive attribute for FSCs. 'Safety', 'seat comfort', 'cabin storage space', 'food and beverages' and 'quality of in-flight meals' were attractive attributes for LCCs and 
one-dimensional attributes for FSCs. For human services, of the five attributes, 'appearance of employees' were found to be attractive attributes for LCCs and one-dimensional attributes for FSCs. The remaining four attributes showed the same results, and in particular, 'uniforms of employees' were found to be indifferent quality features for both airline types. For system related services, 'seat assignment' was a one-dimensional attribute for LCCs and an attractive element for FSCs, while the 'timeliness' of flights was an attractive attribute for LCCs and one-dimensional attributes for FSCs. All other attributes were found to be one-dimensional attributes for both airline types.

Table 5. Service quality attributes by Kano model

\begin{tabular}{|c|c|c|c|}
\hline \multirow{2}{*}{ Factors } & \multirow{2}{*}{ Quality Attributes } & \multicolumn{2}{|c|}{ Classifications } \\
\hline & & LCC & FSC \\
\hline Aircraft & $\begin{array}{l}\text { 1. attractive ticket fare } \\
\text { 2. safety } \\
\text { 3. comfort of the seats } \\
\text { 4. state-of-the-art in flight equipment } \\
\text { 5. cabin storage space }\end{array}$ & $\begin{array}{l}\underline{\mathrm{O}} \\
\underline{\mathrm{M}} \\
\underline{\mathrm{M}} \\
\mathrm{M} \\
\underline{\mathrm{M}}\end{array}$ & $\begin{array}{l}\underline{\mathrm{M}} \\
\underline{\mathrm{O}} \\
\underline{\mathrm{O}} \\
\mathrm{M} \\
\underline{\mathrm{O}}\end{array}$ \\
\hline In-flight service & $\begin{array}{l}\text { 6. availability of meal service } \\
\text { 7. quality of the food \& beverage } \\
\text { 8. in-flight entertainment } \\
\text { 9. cabin cleanliness }\end{array}$ & $\begin{array}{l}\frac{\mathrm{M}}{\mathrm{M}} \\
\frac{\mathrm{M}}{\mathrm{O}}\end{array}$ & $\begin{array}{l}\underline{\mathrm{O}} \\
\underline{\mathrm{O}} \\
\underline{\mathrm{O}} \\
\mathrm{O}\end{array}$ \\
\hline Employee & $\begin{array}{l}\text { 10. appearance of employees } \\
\text { 11. kindness of employees } \\
\text { 12. uniforms of employee } \\
\text { 13. business knowledge \& skills } \\
\text { 14. speed handling request }\end{array}$ & $\begin{array}{l}\frac{\mathrm{M}}{\mathrm{O}} \\
\mathrm{I} \\
\mathrm{O} \\
\mathrm{O}\end{array}$ & $\begin{array}{l}\underline{\mathrm{O}} \\
\mathrm{O} \\
\mathrm{I} \\
\mathrm{O} \\
\mathrm{O}\end{array}$ \\
\hline Flight system & $\begin{array}{l}\text { 15. convenience of booking \& ticketing } \\
\text { 16. convenient flight schedules } \\
\text { 17. easy to refund } \\
\text { 18. speed of check-in } \\
\text { 19. seat assignment } \\
\text { 20. timeliness of flight } \\
\text { 21. on-time luggage delivery }\end{array}$ & $\begin{array}{l}\mathrm{O} \\
\mathrm{O} \\
\mathrm{O} \\
\mathrm{O} \\
\underline{\mathrm{O}} \\
\underline{\mathrm{M}}\end{array}$ & $\begin{array}{l}\mathrm{O} \\
\mathrm{O} \\
\mathrm{O} \\
\mathrm{O} \\
\underline{\mathrm{M}} \\
\underline{\mathrm{O}} \\
\mathrm{O}\end{array}$ \\
\hline A:att & M:must-be, I:indifferent, O:one-dime & & \\
\hline
\end{tabular}




\section{Discussions and Conclusions}

The survival of companies depends on the ability to effectively develop and provide services or products desired by consumers. Competition is becoming fiercer in the airline market due to the introduction and growth of LCCs that are based on low flight fares. Thus, this study applied the Kano model to conduct research on the different perceptions of consumers for services (physical, human, system) offered by LCCs and FSCs. Current study showed interesting results in terms of the classification of service quality attributes for each airline. The summary of results and implications based on the findings are as follows.

First, upon classifying the quality properties of each attribute through the Kano model analysis method, LCCs and FSCs showed different quality properties according to the service item. Of the 21 airline service quality attributes, 10 items that showed different quality properties such as airline fare, safety, seat comfort, cabin cargo space, food and beverage and its quality, in-flight entertainment, employee appearance, seat assignment, and timeless.

Second, in physical service, advanced cabin facilities and cabin cleanliness showed the same results as attractive attributes and one-dimensional attributes, respectively. For all other items, they were one-dimensional attributes for FSCs, while they were all attractive attributes for LCCs. This may imply that the expectations of consumers for FSCs are higher than that for LCCs. Meanwhile, LCCs had more attractive attributes, which can be interpreted as having more opportunities to attract customers. It also dignifies that continuous improvements in services for attractive attributes are necessary in order to gain a competitive advantage among LCCs.

Third, for human service, employee appearance was found to be one-dimensional attribute for FSCs and attractive attribute for LCCs, while all other items were found to be the same. Employee uniforms were found to be indifferent attribute for both airline types, while employee hospitality, work skill, and prompt response were found to be one-dimensional attributes as basic service qualities that airline employees should possess, and can be understood that their expectations are the same for FSCs and LCCs.

Lastly, for system services, seat assignments were found to be attractive attributes for FSCs and one-dimensional qualities for LCCs, while the timeliness of flights were found to be one-dimensional qualities for FSCs and attractive qualities for LCCs.

From the standpoint of customers, higher quality services are expected from FSCs as they pay more in airfare compared to LCCs. The reason why most of the service attributes of FSCs were found to be one-dimensional quality properties in this study is most likely due to this. In result, FSCs must develop new attractive quality attributes such as in-flight entertainment (games, wifi, etc)to attract more customers, and since many of the items are perceived as one-dimensional qualities, more efforts must be made to maintain their service quality. Meanwhile, though LCCs are airlines that provide service by minimizing additional services for the sake of cheaper prices, customers view human and system service to be naturally offered even if they are low-cost carriers. Thus, efforts should be made to attract more customers by establishing marketing strategies and efforts to improve services of items found to be attractive properties, while maintain their existing service qualities.

In terms of limitation of this study, because this study was limited to Incheon Airport and Gimpo Airport for collecting samples, it shows limitations in that the range of the specimens and research were not expanded and that many of the specimens were female. Thus, in future research, efforts must be made to balance the gender ratio of the study group. Furthermore, it is necessary to make comparisons and analyses on whether there are differences in perception of service qualities according to the number of usage and genders of each airline company by detailed service quality research such as mileage services and various partnership services that this study did not deal with. Lastly, through comparative studies research that can present more practical plans for procuring distinguished competitiveness among LCCs in the future. 


\section{References}

1. F.F. Reichheld, Harvard Business Review, 71, 2 (1993)

2. Y.K. Kim, Y.B. Kim, and Y.I. Lee, Total. Qual. Manage, 22, 10,1041-1056 (2011)

3. F. Sultan and M. C. Simpson Jr., J. Serv. MKT, 14, 3,188-216(2000)

4. C.C. Chou, L.L. Liu, S.F. Huang, J.M. Yih and T.C. Han, Applied Soft Computing, 11, 2, 2117-2128 (2011)

5. J.R.B. Ritchie and V.J. Jones, J. T. R, 19 17-25(1980)

6. L.D. Etherington and T. Var, J. T. R, 31, 2, 49-51 (1984)

7. R.S. Toh and M. Y. Hu, Trans. J, Winter, 11-22(988)

8. L.F. Cunningham, C.E. Young and M. Lee, J. Air. Trans, 7 (2002)

9. J.H. Liou and G.H. Tzeng, J. Trans. Manage, 7, 2, 103-109 (2007)

10. A. Shahin and N. Nekuie, The Asian J. Qual, 12, 2, 176-188 (2007)

11. C.C. Leong, J. Qual. Assur. Hospitality \& Tourism, 8, 3 39-59 ((2008)

12. J.W. De Jager, D. Van Zyl and A.L. Toriola, J. Air. Trans. Manage, 7, 2, 103-109 (2011)

13. K. Matzler, M, Fuchs, and A.K. Schubert, Total Qual. Manage, 15 (2004) 9-1 (2004)

14. N. Kano, N. Seraku, F. Takahashi, and S. Tsuji, J. Japanese. Society. Qual. Cont, 14 39-48 (1984) 